\title{
How Do Social-Psychological Concerns Impede the Delivery of Care to People with HIV? Issues for Dental Education
}

\author{
Edward J. Rohn, M.A.; Andrea Sankar, Ph.D.; Diane C. Hoelscher, D.D.S., M.S.; \\ Mark Luborsky, Ph.D.; Mary H. Parise, D.D.S.
}

Abstract: Oral health is an essential aspect of the overall medical care for patients with HIV. However, fear of status disclosure is a significant barrier to access to care. Preparing future oral health care providers to maintain all aspects of confidentiality and to understand the role stigma plays in the lives of HIV-positive individuals are critical issues that must be addressed by dental education. To provide important perspectives regarding HIV-related stigma and confidentiality, data from the HAART (Highly Active Antiretroviral Therapy) Project is presented. This study is a five-year National Institute of Allergy and Infectious Disease (NIAID)funded longitudinal qualitative study of sero-positive African Americans' adherence to antiretroviral therapy ( $N=137)$. The current literature regarding HIV patient confidentiality and student attitudes regarding HIV/AIDS is also reviewed. Findings suggest that dental student attitudes may be improved by providing more comprehensive experiences and information and that procedures in place in dental clinics should be continuously monitored to ensure that patient confidentiality is maintained. Strategies for addressing these important issues in dental education are presented. Ensuring that dental school graduates are well prepared to maintain confidentiality with sensitivity to the role stigma plays in HIV disease has the potential to enhance access to health care.

Mr. Rohn is a Research Associate, Department of Anthropology, Wayne State University; Dr. Sankar is Professor, Department of Anthropology, Wayne State University; Dr. Hoelscher is Chair, Department of Patient Management, University of Detroit Mercy School of Dentistry; Dr. Luborsky is Professor, Department of Anthropology, Wayne State University; and Dr. Parise is Director of Predoctoral Patient Care, Department of Patient Management, University of Detroit Mercy School of Dentistry. Direct correspondence and requests for reprints to Mr. Edward J. Rohn, The HAART Project, 87 E. Ferry, \#61 Knapp Building, Detroit, MI 48202; 313-875-4493 phone; 313-875-4249 fax; e.rohn@wayne.edu.

This project was funded by the National Institute of Allergy and Infectious Disease (NIAID), Grant\# R01 AI 49113.

Key words: HIV/AIDS, confidentiality, stigma, dental students, dental education, access to care, Code of Ethics, HIPAA

Submitted for publication 5/1/06; accepted 7/20/06

$\mathrm{D}$ uring a dental prophylaxis appointment at a local dental school, the first author overheard a fourth-year dental student's discussion with another patient. The student inquired about the current state of the patient's HIV infection and his most recent white blood cell and viral load counts and named the infectious disease clinic where his patient received HIV-related care, a clinic housed on another floor of the same building. The patient answered the dental student's questions quietly, while the student continued to speak at a normal volume. Other patients were in close proximity as the chairs in this clinic are arranged in groups of four in a single bay. Without realizing it, this student disclosed his patient's status by discussing private health issues at a clear and audible volume, easily overheard by all in the immediate area. Although he continued to treat the patient and seemed unburdened personally by treating an HIV-positive patient, his actions may be seen as being in violation of the HIPAA Privacy Rule, as well as the ADA Principles of Ethics and Code of Professional Conduct. ${ }^{1}$
How common is this type of occurrence? Do dental education institutions adequately understand and address confidentiality issues, especially as related to HIV, and are they effectively preparing future dental professionals in this area? What role does stigma - the negative feelings, beliefs, or behavior directed toward an individual or group due to a particular label or characteristic - play in confidentiality and access to care for those with HIV? This article addresses these issues and makes recommendations to improve the ways we manage confidentiality of HIV patients in dental education institutions.

To provide an important perspective regarding HIV-related stigma and confidentiality, data from the HAART (Highly Active Antiretroviral Therapy) Project is presented. The HAART Project is a five-year National Institute of Allergy and Infectious Disease (NIAID)-funded longitudinal qualitative study of sero-positive African Americans' adherence to antiretroviral therapy $(\mathrm{N}=137)$. A multi-method design was employed that included open-ended questions, narratives, standardized psychosocial assessments, 
and clinical markers of adherence (CD4, viral load, genotype). Data reported in this article are from a content analysis of open-ended questions assessing HIV-related stigma and confidentiality.

\section{Oral Health and HIV}

In Western industrialized countries, HIV/AIDS is becoming a chronic illness as a result of the success of antiretroviral therapy. ${ }^{2}$ As mortality continues to decrease, ${ }^{3-5}$ it is likely that the number of sero-positive patients seeking dental care will rise. HIV-positive patients must achieve and maintain a "functional oral health status in order to receive proper nutrition, prevent oral infections, and improve their quality of life." 6 Poor oral health leads to pain that can hinder eating, compromise proper nutrition, and leave sero-positive individuals susceptible to the progression of their illness. ${ }^{7,8}$ Although effective dental treatments exist to avoid this outcome, HIV-positive individuals often face significant barriers to accessing dental care.

Numerous studies have highlighted the unmet oral health needs of people living with HIV/AIDS. A national study of 2,864 sero-positive patients revealed that nearly one in five had perceived unmet oral health needs in the prior six months, a proportion substantially greater than in the general population, with the highest portion being those with incomes less than $\$ 5,000$ annually. ${ }^{9}$

The importance of oral health care and challenges to accessing it are key concerns for a number of the participants in the HAART Project. For example, one study participant described the following experience:

"The medicine is causing my teeth to fall out. I can't receive any type of dental attention. I went to the Family Independence Agency. They told me all they could do for me is pull a tooth. So I asked them, so what you're telling me is that I just have to sit around and deteriorate then. . . . Okay, so pretty soon I'll be toothless. You won't even give me any dentures. And how am I gonna leave my apartment then? So all the denial that I'm receiving from the system is causing me to become a hermit. I spend all of my time at home." (Fifty-three-year-old male)

And later, as the problem progressed, the same person observed:

"No teeth . . . can't chew. . . . Large amounts of food going into my stomach that can't be digested. . . . Now the eating, the nutrition thing is I think my biggest fear because ... I can't gain weight."

\section{Confidentiality as a Barrier to Access}

A person is assured protection by law against unreasonable, substantial, or serious interference with his or her privacy, particularly personal and medical information. ${ }^{10}$ The Health Insurance Portability and Accountability Act (HIPAA) regulations and the Americans with Disabilities Act (ADA) protect people with HIV and their right to control disclosure of their status. ${ }^{10}$ A recent national study of oral health findings for HIV-positive dental patients revealed that 18 percent of patients had not disclosed their HIV status to their dentist and 8 percent of respondents did not trust their dentist to preserve their privacy. ${ }^{11}$ Concerns about confidentiality have also been shown to be a major barrier in seeking not only dental care, but all medical services, highlighting the broad importance of complying with HIPAA regulations and other confidentiality laws. ${ }^{9,12-15}$

Patients may view confidentiality as an issue of respect. For example, in a focus group study of self-reported needs of people living with HIV, Sankar and Luborsky found that "being treated like a human being" was the most frequently expressed need. ${ }^{16}$ In addition, information-collecting systems used by health care institutions may lead to confidentiality concerns for patients. One participant in these focus groups stated:

"I find my confidentiality has been breached by going to a doctor's office and you fill out this thing then it has, 'Do you have so-andso?' And this does not even go to the doctor. ... So when I was given my paper back and it was the date and time and all the blood work and whatever is on there, and down at the bottom where somebody-where I wouldn't have noticed it, it had 'HIV positive' on there." 16

The American Dental Association Principles of Ethics and Code of Professional Conduct (ADA Code $)^{1}$ states specifically that confidentiality must be observed, but refers primarily to patient records. A review of back issues of the Journal of Dental Education 
to March of 1968 found thirty-seven articles addressing confidentiality, but only in the context of electronic usage, moving, and manipulation of patient records. ${ }^{17}$ Other areas addressed by the dental profession relate to referrals (specifically the ADA Code requires a referring dentist to have the written approval of a seropositive patient before revealing his status to the new dentist $^{1}$ ), employment issues, ${ }^{18}$ or blood exposure. ${ }^{19}$ Although "vigilance in handling information that may reveal a patient's identity or diagnosis is required," ${ }^{20}$ the treatment of confidential health information beyond patient records (e.g., during oral communications such as conversations) is not broadly addressed in the ADA Code or in the dental literature.

However, the American Dental Association does have clear guidelines regarding the treatment of HIV-positive patients. Treatment may not be withheld because the patient refuses to be tested for HIV. AIDS patients cannot be refused emergency dental care, and there are no medical reasons why HIV patients may be denied treatment, regardless of any reason given by the dentist. ${ }^{8,10}$ Overall, "the benefit of the patient," HIV-positive or not, remains the primary goal. ${ }^{1}$

\section{HIV Stigma and Dental Professionals}

Stigma is experienced as negative treatment resulting from a perceived "attribute that reduces a person in the minds of others from a whole and usual person to a tainted, discounted one."21,22 Patient concerns about HIV stigma and negative attitudes toward sero-positive patients by health care providers can violate patient trust and degrade the hope and confidence necessary to begin and sustain HIV treatment. ${ }^{12,14,15}$ Dentistry is not exempt from treatment of patients that is potentially stigmatizing. In one study, a patient alerted her dentist to her HIV status, and he then questioned her about her symptoms and cell counts. He agreed to treat her "for right now," but told her that when her HIV had progressed to a "bad" level, she would be dismissed from treatment. ${ }^{14}$ Another woman revealed her sero status to a dental hygienist, who stopped in the middle of the examination and left the building, quitting her job. ${ }^{14}$ In Sankar and Luborsky's focus group study, participants felt that health care providers could be "concrete and localized sources of stigma." " Such behavior is clearly not ethical and serves to illustrate that there may be a disconnect between what dental professionals are taught and what they take to practice.
Studies of dental students have revealed that, despite a professional obligation to treat sero-positive patients, prejudice and views regarding cultural and sexual diversity may inhibit student attitudes. ${ }^{23,24}$ In one study, 76 percent of students felt dentists had a responsibility to treat HIV-positive patients, but only 62 percent said they were willing to treat those with $\mathrm{HIV}^{25}$ A more recent study found that 6.7 percent of dental and dental hygiene students agreed with the statement, "Because of the level of risk involved in treating homosexual patients, I would prefer not to treat them."${ }^{.6}$ Predictors for negative attitudes toward patients with HIV include lack of professional identity and discomfort with homosexuality. ${ }^{24}$ Further, dentists' decisions not to treat are linked to notions of professional autonomy and may be complicated by an inflated sense of transmission risk. ${ }^{10}$

Two studies found no significant difference in attitudes toward HIV patients between first- and fourth-year dental students, suggesting that increased professional knowledge does not lead to increased acceptance. ${ }^{24,25}$ However, other studies have shown that knowledge relates positively to willingness to treat HIV patients..$^{27,28}$ Kuthy et al. found that previous experiences treating vulnerable populations, including HIV/AIDS patients, had a positive effect on perceived future willingness to treat and comfort level with treating these patients. ${ }^{29}$ Also, in a survey by Seacat and Inglehart, dental and dental hygiene students indicated that treatment with clinical supervision of HIV-positive patients would give them more confidence in treating these patients in the future. ${ }^{26}$ Although it is difficult to change student attitudes, these studies do provide some encouragement regarding opportunities to both influence student attitudes regarding HIV disease and increase awareness of confidentiality issues in dental education.

\section{How HIV Stigma and Confidentiality Affect Access to Care}

Disclosing one's HIV status is very much a "reasoned action" where the risks associated with potential stigma are balanced against increased access to health care benefits, potential social support, and relief derived from sharing an important secret. ${ }^{30}$ Volunteers in the HAART Project have relayed numerous ways of "testing the water" before disclosing their sero status, including bringing up the topic of 
HIV/AIDS, other illnesses, homosexuality, or world problems, like war or poverty, to gauge the listener's overall sensitivity and understanding.

Further, people with HIV may be protecting others in their lives from prejudice and discrimination. Family members, particularly children, are perceived by sero-positive persons to be at risk for negative treatment and stigma by association. ${ }^{31}$ Some have chosen not to tell their families or, in the case of children, are waiting until they are mature enough to handle the information. ${ }^{30}$ Breach of confidentiality significantly compromises the patient's right to control who knows their status.

Confidentiality concerns and fear of stigma may also affect the accuracy of information obtained from HIV patients. Procedures used in clinics for collecting patient information may not appear to be confidential to HIV patients. The paperwork that patients are asked to fill out at most dentists' offices and dental school clinics asks directly about HIV status. ${ }^{16}$ Patients may leave these questions unanswered because they don't feel it is anyone's business, especially if these papers will be reviewed by a member of the support staff before reaching the dentist. Despite expectations by sero-positive patients that people in the health care field are well educated about and therefore more accepting of people with HIV, many find this not to be true. ${ }^{14}$

Given the success of antiretroviral medications, stigma can become the "central force" by which people feel the effects of having HIV, ${ }^{32}$ meaning that disclosure can be a more significant concern than the physical manifestations of the disease. ${ }^{14}$ When a clinician is the source of a breach in confidentiality, it weakens the clinician-patient relationship and can limit or prevent a patient's future access to health care. One negative experience has the potential to affect future relationships with any clinician.

\section{Implications for Dental Education}

Dental schools are increasingly integrating ethics into their curricula. ${ }^{33}$ The focus to date has been primarily on academic integrity, principles of ethics, and professional conduct. Although the need to maintain confidentiality is recognized as part of the ADA Code, ${ }^{1}$ it was not directly addressed in the ethics curricula discussed in a recent review of the field. ${ }^{33}$

Clearly, there is a definite need to provide instruction and experiences to dental and allied dental students beyond the context of general ethical obligations. Specific instruction regarding confidentiality and the potential effect it has on access to care should be included. Many schools may be already providing this instruction. Increasing awareness and the inclusion of content addressing diversity issues may also help support greater understanding of the role stigma can play in access to health care. Although some studies suggest that little can be done to mold the attitudes and misconceptions of students towards HIV/AIDS, ${ }^{23-25}$ other studies support providing knowledge and experiences as a means of positively affecting attitudes. ${ }^{27,28}$

How can this be accomplished? We believe that providing instruction in ethics and HIPAA privacy policies is not enough. While each school should assess its own situation and develop individual solutions, strategies for more effectively addressing confidentiality and the stigma associated with HIV may include the following:

- If possible, invite HIV-positive individuals to speak with students to share their perspectives as patients.

- Ask faculty to model appropriate ways of interacting with patients with sensitive health care information.

- Conduct periodic in-service training for students, staff, and faculty to reinforce policies and to keep awareness of confidentiality issues high.

- Formalize evaluation of student competency in maintaining patient confidentiality (e.g., OSCE items, including criteria related to confidentiality in other clinical exams).

- Provide role-playing opportunities for students as they enter the clinic so they have the opportunity to apply what is learned in the classroom to clinical situations.

- Carefully examine how clinics work from patients' perspective to look for ways their privacy may be compromised.

- Evaluate how staff interact with patients in nontreatment areas to be sure that privacy is maintained (this has been reported to be a major issue for patients).

- Continually be open to address issues as they arise.

After the incident that opened this article was reported to the dental school administration, the school scheduled a series of training sessions for all fourth-year dental students. Students and faculty both became more aware of confidentiality issues and adjusted their communications with patients to 
reduce the chance of being overheard by others in the immediate area.

\section{Conclusion}

Attention to the need for confidentiality provides educational opportunities for both ethical behavior and the larger social implications of oral health. The role oral health care plays in HIV treatment is clear: good oral health is important in maintaining proper nutrition, which is the key to maintaining one's overall health and increasing life expectancy. However, concerns about confidentiality may prevent people from accessing oral health care services. Ensuring that graduates are well prepared to maintain confidentiality with sensitivity to the role stigma plays in HIV disease has the potential to enhance patients' access to health care. This can go a long way toward preserving the quality of life for HIV-positive patients.

\section{REFERENCES}

1. Principles of ethics and code of professional conduct. Chicago: American Dental Association, 2005.

2. Pierret J. Everyday life with AIDS/HIV: surveys in the social sciences. Soc Sci Med 2000;50:1589-98.

3. Hirsch HH, Kaufmann G, Sendi P, Battegay M. Immune reconstruction in HIV-infected patients. Clin Infect Dis 2004;38:1159-66.

4. Reynolds NR. Adherence to antiretroviral therapies: state of the science. Curr HIV Res 2004;2:207-14.

5. Wood E, Hogg RS, Yip B, Harrigan RP, O'Shaughnessy MV, Montaner JS. The impact of adherence on CD4 cell count responses among HIV-infected patients. J Acquir Immune Defic Syndr 2004;35:261-8.

6. Zabos GP. Meeting primary oral health care needs of HIVinfected women. Am J Public Health 1999;89:818-19.

7. Glick M. Dental management of patients with HIV. Chicago: Quintessence Publishing Co., 1994.

8. Little JW, Falace DA, Miller CS, Rhodus NL. Dental management of the medically compromised patient. 5th ed. St. Louis: Mosby, 1997.

9. Marcus M, Freed JR, Coulter ID, et al. Perceived unmet need for oral treatment among a national population of HIV-positive medical patients: social and clinical correlates. Am J Public Health 2000;90:1059-63.

10. Doyal L. Good ethical practice in the dental treatment of patients with HIV/AIDS. Oral Dis 1997;3:S214-S220.

11. Freed JR, Marcus M, Freed BA, Der-Martirosian C, Maida CA, Younai FS, et al. Oral health findings for HIV-infected adult medical patients from the HIV cost and services utilization study. J Am Dent Assoc 2005;136:1396-405.

12. Chesney MA, Smith AW. Critical delays in HIV testing and care. Am Behav Sci 1999;42:1158-70.

13. Raveis VH, Siegel K, Gorey E. Factors associated with HIV-infected women's delay in seeking medical care. AIDS Care 1998;10:549-62.
14. Carr RL, Gramling LF. Stigma: a health barrier for women with HIV/AIDS. J Assoc Nurses AIDS Care 2004;15: $30-9$.

15. Sowell RL, Seals B, Moneyham L, Guillory J, Demi A, Cohen L. Barriers to health-seeking behaviors for women infected with HIV. Nurs Connect 1996;9:5-17.

16. Sankar A, Luborsky M. Developing a community-based definition of needs for persons living with chronic HIV. Hum Org 2003;62:153-65.

17. Barnett ML. University-industry relationships in dentistry: past, present, and future. J Dent Educ 2002;66:1163-8.

18. Crumpler DC, Carey M. Employment considerations of AIDS in dental institutions. J Dent Educ 1987;51: 465-70.

19. Younai FS, Murphy DC, Kotelchuck D. Occupational exposure to blood in dental teaching environment: results of a ten-year surveillance study. J Dent Educ 2001;65: 436-48.

20. Surlis S, Hyde A. HIV-positive patients' experiences of stigma during hospitalization. J Assoc Nurses AIDS Care 2001;12:68-77.

21. Goffman E. Stigma: notes on the management of spoiled identity. New York: Simon \& Schuster, 1963.

22. Luborsky M. The cultural adversity of physical disability: erosion of full adult personhood. J Aging Stud 1994;8: 239-53.

23. Driscoll JM, Hoffman MA. Exploring attitudes of white dental students regarding willingness to treat people with HIV. J Dent Educ 1997;61(9):717-26.

24. Bennett ME, Weyant RJ, Simon M. Predictors of dental students' belief in the right to refuse treatment to HIVpositive patients. J Dent Educ 1993;57:673-9.

25. Anderson DG, Call RL, Vojir CP. Differences in HIV knowledge and attitudes between first- and fourth-year dental students. J Dent Educ 1994;58:668-72.

26. Seacat JP, Inglehart MR. Education about treating patients with HIV infections/AIDS: the student perspective. J Dent Educ 2003;67:630-40.

27. Borsum KM, Gjermo PE. Relationship between knowledge and attitudes regarding HIV/AIDS among dental school employees and students. Eur J Dent Educ 2004;8(3): 105-10.

28. Erasmus S, Luiters S, Brijlal P. Oral hygiene and dental students' knowledge, attitude, and behaviour in managing HIV/AIDS patients. Int J Dent Hyg 2005;3:213-7.

29. Kuthy RA, McQuistan MR, Riniker KJ, Heller KE, Qain F. Students' comfort level in treating vulnerable populations and future willingness to treat: results prior to extramural participation. J Dent Educ 2005;69:1307-14.

30. Moneyham L, Seals B, Demi A, Sowell R, Cohen L, Guillory J. Experiences of disclosure in women infected with HIV. Health Care Women Int 1996;17:209-21.

31. Sankar A, Luborsky M, Schuman P, Roberts G. Adherence discourse among HIV+ African American women taking high acting antiretroviral therapy. AIDS Care 2002;14:203-18.

32. Fife BL, Wright ER. The dimensionality of stigma: a comparison of its impact on the self of persons with HIV/AIDS and cancer. J Health Soc Behav 2000;41:50-67.

33. Berk NW. Teaching ethics in dental schools: trends, techniques, and targets. J Dent Educ 2001;65:744-50. 